ISSN : $2450-766 X$

\title{
SIMULASI PENANGANAN PENCILAN PADA ANALISIS REGRESI MENGGUNAKAN METODE LEAST MEDIAN SQUARE(LMS)
}

\author{
Tusilowati ${ }^{1}$, L. Handayani², dan Rais ${ }^{3}$ \\ 1,2,3Program Studi Statistika Jurusan Statistik FMIPA Universitas Tadulako \\ Jalan Soekarno-Hatta Km. 09 Tondo, Palu 94118, Indonesia. \\ 1tusilowati02@gmail.com, 2lilies.stath@gmail.com, ${ }^{3}$ rais76_untad@yahoo.co.id
}

\begin{abstract}
The simulation of handling of outliers on regression analysis used the method which was commonly used to predict the parameter in regression analysis, namely Least Median Square (LMS) due to the simple calculation it had. The data with outliers would result in unbiased parameter estimate. Hence, it was necessary to draw up the robust regression to overcome the outliers. The data used were simulation data of the number of data pairs ( $X, Y)$ by 25 and 100 respectively. The result of the simulation was divided into 5 subsets of data cluster of parameter regression prediction by Ordinary Least Square (OLS) and Least Median Square (LMS) methods. The prediction result of the parameter of each method on each subset of data cluster was tested with both method to discover the which better one. Based on the research findings, it was found that The Least Median Square (LMS) method was known better than Ordinary Least Square (OLS) method in predicting the regression parameter on the data which had up to $3 \%$ of the percentage of the outlier.
\end{abstract}

Keywords $\quad$ : Regression Analysis, Least Median Square (LMS), Outlier Data of Robust Regression.

\section{ABSTRAK}

Simulasi Penanganan Pencilan Pada Analisis Regresi Menggunakan Metode yang umum digunakan untuk menduga parameter dalam analisis regresi adalah Least Median Square(LMS) karena memiliki perhitungan yang sederhana. Data yang memiliki pencilan akan menghasilkan dugaan parameter yang takbias. Sehingga perlu disusun metode regresi kekar untuk mengatasi pencilan. Data yang digunakan adalah data simulasi banyaknya pasangan data $(X, Y)$ sebesar masing-masing 25 dan 100. Hasil simulasi diperoleh data yang terbagi menjadi 5 subset gugus data parameter regresi diduga dengan metode Ordinary Least Square (OLS) dan Least Median Square (LMS). Hasil dugaan parameter masing-masing metode pada setiap subset gugus data diuji dengan kedua metode untuk mengetahui metode mana yang lebih baik. Dari hasil penelitian diperoleh Metode Least Median Square (LMS) lebih baik dari pada metode Ordinary Least Square (OLS) dalam penduga parameter regresi pada data yang memiliki pencilan hingga persentase pencilan sebesar $3 \%$.

Kata kunci : : Analisis Regresi, Least Median Square (LMS), data pencilan Regresi Kekar (Robust). 


\section{PENDAHULUAN}

\subsection{Latar Belakang}

Analisis regresi adalah metode statistika yang memanfaatkan hubungan antara dua atau lebih peubah kuantitatif sehingga salah satu peubah dapat diramalkan dari peubah lainnya (Draper dan Smith, 1992). Peubah tersebut dibedakan menjadi dua, yaitu peubah bebas dan peubah tak bebas. Analisis regresi adalah metode yang sangat populer untuk mengetahui hubungan linier antara variabel respon dengan satu atau lebih peubah bebas. Metode pendugaan parameter regresi yang paling populer adalah Ordinary Least Square (OLS). Metode ini populer karena selain pertama kali dikembangkan juga dianggap paling mudah. Setiap metode selalu memiliki kelebihan dan kekurangan. OLS akan sahih jika sejumlah asumsi tertentu dipenuhi.

Metode ordinary least square (OLS) adalah metode pendugaan dengan meminimumkan jumlah kuadrat galat. Metode ini cenderung memiliki perhitungan yang sederhana. Sejumlah asumsi yang harus dipenuhi adalah tidak adanya multikolinieritas antar peubah bebas, galat menyebar mengikuti sebaran normal, galat memiliki ragam yang homogeny (homoskedastisitas), dan antar komponen galat tidak terjadi autokorelasi. Salah satu asumsi yang cukup sulit untuk dipenuhi adalah asumsi tidak adanya multikolinieritas (korelasi kuat antar peubah bebas) dikarenakan jumlah peubah bebas yang cukup banyak. Untuk mengatasi pelanggaran asumsi tersebut dikembangkan beberapa alternatif. Alternatif tersebut adalah regresi komponen utama, membuang salah satu peubah bebas yang berkorelasi, atau dengan regresi.

Myers (1990) menyatakan bahwa apabila asumsi terpenuhi maka penduga parameter yang diperoleh bersifat BLUE (best linier unbiased estimator). Padahal permasalahan yang sering dihadapi yaitu adanya asumsi yang dilanggar. Salah satu penyebab dilanggarnya asumsi ialah adanya pencilan (outlier) pada data. Adanya pencilan pada regresi menggunakan metode OLS merupakan masalah, karena OLS sensitif terhadap pencilan dimana persamaan regresi yang dihasilkan oleh OLS cenderung mudah berubah-ubah. Salah satu metode untuk mengatasi pencilan yang paling populer digunakan adalah regresi kekar dengan pendekatan least median square (LMS).

Metode LMS adalah salah satu metode estimasi regresi yang diperkenalkan oleh Andrews (1972). Metode ini melakukan perhitungan dengan menghilangkan pengaruhpengaruh sisaan. Dengan menggunakan penduga yang dihasilkan akan lebih baik dalam menghadapi pencilan. Kriteria dari LMS adalah metode analisis standar dari data ketika adanya kemungkinan banyaknya data pencilan, dimana estimasi terhadap nilai pengganggu tetap dimungkinkan (Rousseeuw, 1984). Dalimunthe (2010) menggunakan metode LMS pada analisis regresi dengan pencilan menggunakan PMC. Dalam penelitian ini peneliti akan 
menggunkan regresi kekar dengan metode LMS pada analisis regresi dengan pencilan menggunkan OLS.

\subsection{Rumusan Masalah}

Dari latar belakang di atas peneliti dapat merumuskan permasalahan yaitu bagaimana menentukan pengaruh Ordinary Least Square (OLS) terhadap pendugaan parameter model regresi?.

\subsection{Batasan Masalah}

Dalam peneliti ini, metode digunakan adalah data simulasi banyaknya pasangan data $(\mathrm{X}, \mathrm{Y})$ sebesar masing-masing 25 dan 100.

\section{TINJAUAN PUSTAKA}

\subsection{Variabel Penelitian}

Metode Ordinary Least Square (OLS) adalah estimasi parameter berjutuan mendapatkan model regresi yang akan digunakan dalam analisis regresi. Metode Kuadrat Terkecil ini bertujuan meminimumkan jumlah kuadrat error. (Srinadi, I.G.A.M 2014).

\subsection{Pencilan (Outlier)}

\subsubsection{Pengertian Metode pencilan (Outlier)}

Pencilan adalah suatu data yang menyimpan dari sekumpulan data yang lain ada beberapa definisi pencilan (outlier) menurut para ahli:

\subsubsection{Perumusan Metode pencilan}

diterapkan bila anggaan-anggapan berikut terpenuhi:

a) Menurut Barnett dan Lewis, T. 1994. pencilan adalah pengamatan yang tidak mengikuti sebagian besar pola dan terletak jauh dari pusat data.

b) Menurut Sembiring, R.K Sembing 2005. pencilan adalah pengamatan yang jauh dari pusat data yang mungkin berpengaruh besar terhadap koefesien regresi.

c) Menurut Barnett dan Lewis, T. 1994. pencilan adalah suatu pengamatan yang tampak bertentangan atau tidak konsisten terhadap pengamatan yang lain.

\section{PROSEDUR PENELITIAN}

Prosedur dalam penelitian ini adalah:

1. Memulai penelitian

2. Menentukan topik penelitian untuk dianalisis, serta mempelajari metode pendugaan parameter Ordinary Least Square

3. Mencari dan menyeleksi penelitian yang berkaitan dengan topik penduga parameter

4. Input data yang akan dianalisis melalui pembangkitan data simulasi 
5. Melakukan pemodelan regresi menggunakan metode penduga parameter Ordinary Least Square dan Least Mendian Square

6. Membandingkan model yang dihasilkan menggunkan MAPE

7. Pemilihan model terbaik

8. Interpretasi atau penarikan kesimpulan dari hasil yang diperoleh

9. Selesai

\section{HASIL DAN PEMBAHASAN}

\subsection{Data Penelitian}

Data yang digunakan dalam penelitian ini adalah data bangkitan dengan 6 gugus data dimana 5 gugus data pertama $(n)$ sebanyak 25 disetiap gugus berdasarkan model regresi $Y_{i}=$ $\beta_{0}+\beta_{1} X_{i}+\varepsilon_{i}$ (Tabel 1). Dengan kriteria dan data sebagai berikut:

Tabel 1 : Data Pencilan- $X$

\begin{tabular}{|c|c|c|c|}
\hline Gugus Data & Pencilan- $X$ & Pencilan- $Y$ & Pencilan- $X Y$ \\
\hline 1 & - & - & - \\
\hline 2 & $\sqrt{ }$ & - & $\sqrt{ }$ \\
\hline 3 & - & $\sqrt{ }$ & $\sqrt{ }$ \\
\hline 4 & $\sqrt{ }$ & $\sqrt{ }$ & $\sqrt{ }$ \\
\hline 5 & $\sqrt{ }$ & $\sqrt{ }$ & \\
\hline
\end{tabular}

Ke-5 gugus data di atas akan dibangkitkan dengan menggunakan software $\mathrm{R}$ yang tertera pada Lampiran 1-5. Hasil bangkitan datanya disajikan pada Lampiran 6. Gugus data 1-5 kemudian diregresikan dengan OLS/LMS. Lalu ditentukan nilai $\underline{\beta}, \underline{Y}$ dan $\underline{\varepsilon}$ serta MAPE menggunakan software R. (Gugus data selanjutnya ialah gugus data yang di dalamnya terdapat ke-5 kriteria pada data diatas yaitu:

1. Ditentukan ukuran subset 5 , dengan jumlah subset 5 dan batas kesalahan $\alpha=5 \%$.

2. Membagi secara acak gugus data yang berukuran 25 kedalam 5 buah subset berukuranan 5 . Dilakukan pengulangan $2 x$. 
Tabel 2 : Data Menggunakan OLS Sehingga diperoleh Parameter Setiap Subset

\begin{tabular}{|c|c|c|c|c|c|}
\hline \multicolumn{6}{|l|}{ Pembagian secara acak } \\
\hline & $x$ & $Y$ & & $x$ & Y \\
\hline \multirow{5}{*}{ Subset 1} & 10 & 100 & \multirow{5}{*}{ Subset 1} & 27 & 105 \\
\hline & 7 & 19 & & 13 & 30 \\
\hline & 2 & 13 & & 11 & 33 \\
\hline & 35 & 50 & & 2 & 13 \\
\hline & 17 & 56 & & 9 & 30 \\
\hline \multirow{5}{*}{ Subset 2} & 15 & 42 & \multirow{5}{*}{ Subset 2} & 10 & 30 \\
\hline & 5 & 26 & & 35 & 50 \\
\hline & 27 & 105 & & 7 & 19 \\
\hline & 8 & 21 & & 40 & 92 \\
\hline & 1 & 12 & & 3 & 18 \\
\hline \multirow{5}{*}{ Subset 3} & 16 & 43 & \multirow{5}{*}{ Subset 3} & 25 & 100 \\
\hline & 25 & 100 & & 8 & 21 \\
\hline & 18 & 50 & & 12 & 31 \\
\hline & 9 & 30 & & 5 & 26 \\
\hline & 19 & 50 & & 6 & 22 \\
\hline \multirow{5}{*}{ Subset 4} & 40 & 92 & \multirow{5}{*}{ Subset 4} & 14 & 35 \\
\hline & 20 & 52 & & 17 & 56 \\
\hline & 12 & 31 & & 18 & 50 \\
\hline & 3 & 18 & & 20 & 52 \\
\hline & 13 & 30 & & 19 & 50 \\
\hline \multirow{5}{*}{ Subset 5} & 11 & 33 & \multirow{5}{*}{ Subset 5} & 4 & 17 \\
\hline & 14 & 35 & & 15 & 42 \\
\hline & 4 & 17 & & 16 & 43 \\
\hline & 10 & 30 & & 1 & 12 \\
\hline & 6 & 22 & & 10 & 100 \\
\hline
\end{tabular}

3. Meregresikan dengan menggunakan OLS sehingga diperoleh parameter setiap subset. Mencari median dari kuadrat error disetiap subset. 
Tabel 3 : Data yang diacak ke-1

\begin{tabular}{|c|c|c|c|c|c|}
\hline $\begin{array}{c}\text { Pengacakan } \\
\text { ke-1 }\end{array}$ & $x$ & $y$ & $\hat{y}$ & e & Mede \\
\hline \multirow{5}{*}{ Subset 1} & 10 & 100 & 34.2393 & 65.7607 & \multirow[t]{5}{*}{-31.52139848} \\
\hline & 7 & 19 & 28.3776 & -9.3776 & \\
\hline & 2 & 13 & 18.608 & -5.608 & \\
\hline & 35 & 50 & 83.0872 & -33.087 & \\
\hline & 17 & 56 & 47.9167 & 8.08329 & \\
\hline \multirow{5}{*}{ Subset 2} & 15 & 42 & 44.0089 & -2.0089 & \multirow[t]{5}{*}{46.01775913} \\
\hline & 5 & 26 & 24.4697 & 1.53028 & \\
\hline & 27 & 105 & 67.4559 & 37.5441 & \\
\hline & 8 & 21 & 30.3315 & -9.3315 & \\
\hline & 1 & 12 & 16.6541 & -.46541 & \\
\hline \multirow{5}{*}{ Subset 3} & 16 & 43 & 45.9628 & -2.9628 & \multirow[t]{5}{*}{0.129373152} \\
\hline & 25 & 100 & 63.548 & 36.452 & \\
\hline & 18 & 50 & 49.8706 & 0.12937 & \\
\hline & 9 & 30 & 32.2854 & -2.2854 & \\
\hline & 19 & 50 & 51.8245 & -1.8245 & \\
\hline \multirow{5}{*}{ Subset 4} & 40 & 92 & 92.8568 & -0.8568 & \multirow[t]{5}{*}{-7.147132282} \\
\hline & 20 & 52 & 53.7785 & -1.7785 & \\
\hline & 12 & 31 & 38.1471 & -7.1471 & \\
\hline & 3 & 18 & 20.5619 & -2.5619 & \\
\hline & 13 & 30 & 40.101 & -10.101 & \\
\hline \multirow{5}{*}{ Subset 5} & 11 & 33 & 36.1932 & -3.1932 & \multirow[t]{5}{*}{-5.515806194} \\
\hline & 14 & 35 & 42.055 & -7.055 & \\
\hline & 4 & 17 & 22.5158 & -5.5158 & \\
\hline & 10 & 30 & 34.2393 & -4.2393 & \\
\hline & 22 & 21.775 & 57.6863 & -35.911 & \\
\hline
\end{tabular}


Tabel 4 : Data yang di acak ke-2

\begin{tabular}{|c|c|c|c|c|c|}
\hline Pengacakan ke-2 & $x$ & $y$ & $\hat{y}$ & $\mathrm{e}$ & mede \\
\hline \multirow{5}{*}{ Subset 1} & 27 & 105 & 70.5515 & 35.4485325 & \multirow[t]{5}{*}{-4.049660471} \\
\hline & 13 & 30 & 41.2374 & -11.23739625 & \\
\hline & 11 & 33 & 37.0497 & -4.049660471 & \\
\hline & 2 & 13 & 18.2048 & -5.204849441 & \\
\hline & 9 & 30 & 32.8619 & -2.861924686 & \\
\hline \multirow{5}{*}{ Subset 2} & 10 & 30 & 34.9558 & -4.95579578 & \multirow[t]{5}{*}{-6.74188902} \\
\hline & 35 & 50 & 87.3025 & -37.30248988 & \\
\hline & 7 & 19 & 28.6742 & -9.674188902 & \\
\hline & 40 & 92 & 97.7718 & -5.771829344 & \\
\hline & 3 & 18 & 20.2987 & -2.298717333 & \\
\hline \multirow{5}{*}{ Subset 3} & 25 & 100 & 66.3638 & 33.63618904 & \multirow[t]{5}{*}{-8.143528363} \\
\hline & 8 & 21 & 30.7681 & -9.768056794 & \\
\hline & 12 & 31 & 39.1435 & -8.143528363 & \\
\hline & 5 & 26 & 24.4865 & 1.513546883 & \\
\hline & 6 & 22 & 26.5803 & -4.58032101 & \\
\hline \multirow{5}{*}{ Subset 4} & 14 & 35 & 43.3313 & -8.331264147 & \multirow[t]{5}{*}{-1.706735716} \\
\hline & 17 & 56 & 49.6129 & 6.387132176 & \\
\hline & 18 & 50 & 51.7067 & -1.706735716 & \\
\hline & 20 & 52 & 55.8945 & -3.8944715 & \\
\hline & 19 & 50 & 53.8006 & -3.800603608 & \\
\hline \multirow{5}{*}{ Subset 5} & 4 & 17 & 8.37547 & 8.624528431 & \multirow[t]{5}{*}{-4.518999931} \\
\hline & 15 & 42 & 45.4251 & -3.425132039 & \\
\hline & 16 & 43 & 47.519 & -4.518999931 & \\
\hline & 1 & 12 & 16.111 & -4.110981549 & \\
\hline & 10 & 100 & 34.9558 & 65.04420742 & \\
\hline
\end{tabular}

4. Dengan melihat data diatas, maka diperoleh minimum median: -8.143528363

5. Berdasarkan minimum median, maka diperoleh $\boldsymbol{b}=\left[\begin{array}{c}10.525 \\ 1.875\end{array}\right]$ dari hasil regresi anak gugus yang mempunyai median terkecil pada langkah 4 .

6. Menentukan kuadrat galat: 
Tabel 5 : Langkah 3 dan 4 diperoleh sebagai berikut:

\begin{tabular}{|c|c|c|c|c|c|}
\hline$o b s$ & $x$ & $y$ & $\hat{y}$ & $e_{i}$ & $e_{i}^{2}$ \\
\hline 1 & 1 & 12 & 16.111 & -4.111 & 16.9002 \\
\hline 2 & 2 & 13 & 18.2048 & -5.2048 & 27.0905 \\
\hline 3 & 3 & 18 & 20.2987 & -2.2987 & 5.2841 \\
\hline 4 & 4 & 17 & 22.3926 & -5.3926 & 29.08 \\
\hline 5 & 5 & 26 & 24.4865 & 1.51355 & 2.29082 \\
\hline 6 & 6 & 22 & 26.5803 & -4.5803 & 20.9793 \\
\hline 7 & 7 & 19 & 28.6742 & -9.6742 & 93.5899 \\
\hline 8 & 8 & 21 & 30.7681 & -9.7681 & 95.4149 \\
\hline 9 & 9 & 30 & 32.8619 & -2.8619 & 8.19061 \\
\hline 10 & 10 & 30 & 34.9558 & -4.9558 & 24.5599 \\
\hline 11 & 11 & 33 & 37.0497 & -4.0497 & 16.3997 \\
\hline 12 & 12 & 31 & 39.1435 & -8.1435 & 66.3171 \\
\hline 13 & 13 & 30 & 41.2374 & -11.237 & 126.279 \\
\hline 14 & 14 & 35 & 43.3313 & -8.3313 & 69.41 \\
\hline 15 & 15 & 42 & 45.4251 & -3.4251 & 11.7315 \\
\hline 16 & 16 & 43 & 47.519 & -4.519 & 20.4214 \\
\hline 17 & 17 & 56 & 49.6129 & 6.38713 & 40.7955 \\
\hline 18 & 18 & 50 & 51.7067 & -1.7067 & 2.91295 \\
\hline 19 & 19 & 50 & 53.8006 & -3.8006 & 14.4446 \\
\hline 20 & 20 & 52 & 55.8945 & -3.8945 & 15.1669 \\
\hline 21 & 10 & 100 & 34.9558 & 65.0442 & 4230.75 \\
\hline 22 & 35 & 50 & 87.3025 & -37.302 & 1391.48 \\
\hline 23 & 40 & 92 & 97.7718 & -5.7718 & 33.341 \\
\hline 24 & 25 & 100 & 66.3638 & 33.6362 & 1131.39 \\
\hline 25 & 27 & 105 & 70.5515 & 34.4487 & 1186.7 \\
\hline
\end{tabular}

Menentukan $S_{0}=1.4826\left(1+\frac{5}{N-p}\right) \sqrt{\operatorname{Med} e_{i j}^{2}}=6.948882$

7. Menghitung bobot $w_{i}$, dengan menggunakan $w_{i}=1 j i k a\left|\frac{s_{0}}{e_{i}}\right| \leq \alpha$ dan $w_{i}=$ $\frac{s_{0}}{\left|e_{i}\right|}$ selainnya. 


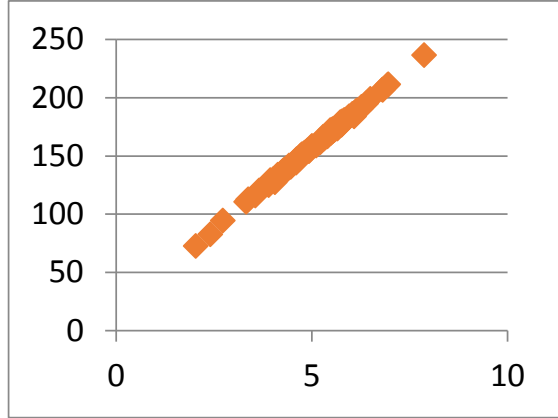

(a)

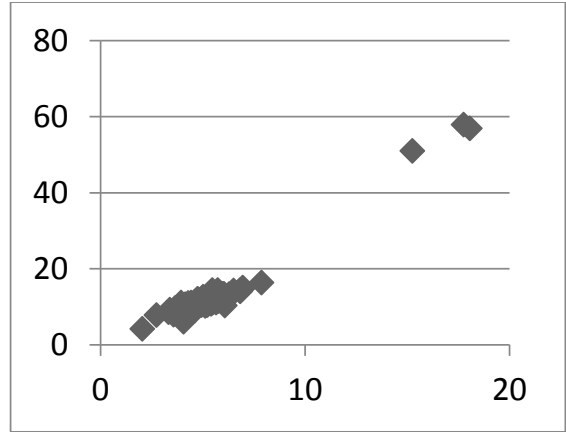

(c)

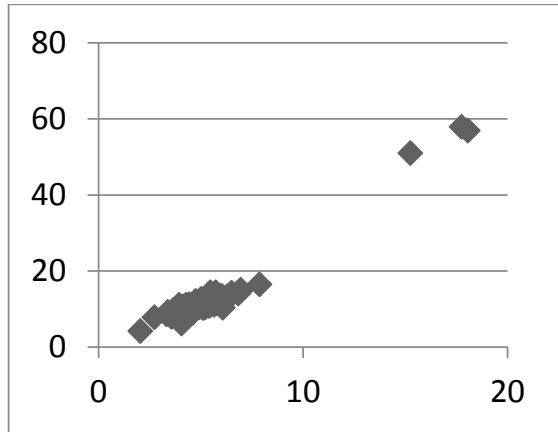

(e)

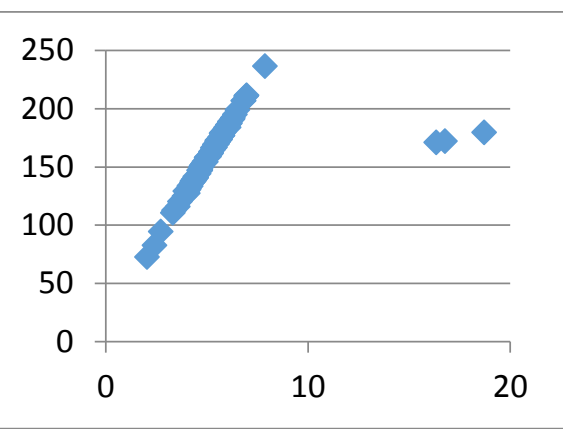

(b)

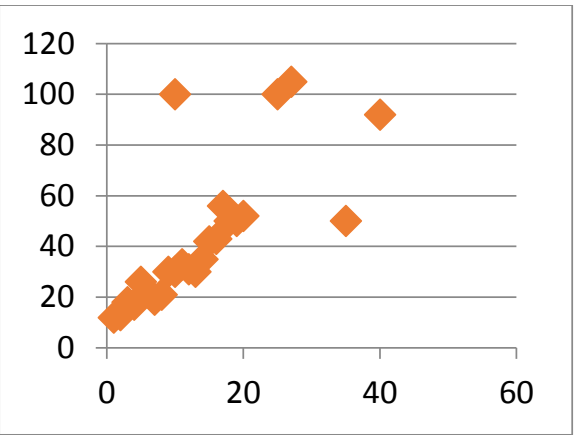

(d)

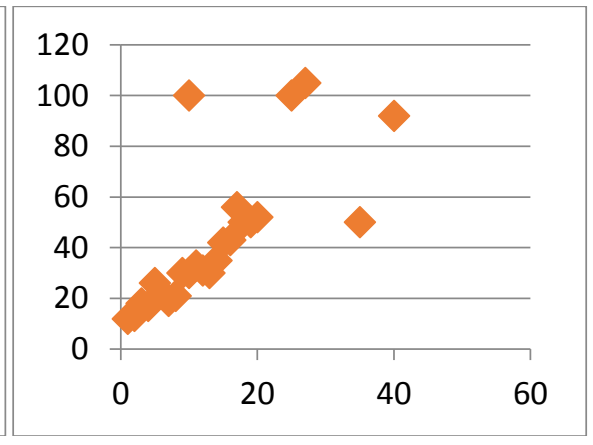

(f)

Gambar 1 : Gugus data yang (a) tanpa pencilan, sedangkan gugus data (b) sampe (f) semua data menggunakan pencilan.

\section{KESIMPULAN}

Berdasarkan cara membangkitkan data untuk menentukan ada tidaknya suatu pencilan dengan menggunakan metode OLS dan LMS, untuk menentukan seberapa besar kekekaran metode Least Median Square (LMS) dalam menduga parameter regresi dari gugus data yang memiliki pencilan. 


\section{DAFTAR PUSTAKA}

[1] Andrew, The most destructive hurricane in United States history ,1972, jakarta.

[2] Daliunthe, Metode Least Median Of Square (LMS) pada Analisi Regresi Dengan Pencilan. Jurusan Departemen Statistika FMIPA ITB, 2010, Bogor.

[3] Draper, Analisis Regresi Terapan Edisi Ke-2, Jakarta PT Gramedia Pusaka Utama. Terjemahan dari Applied Regression Analysis,1992, Jakarta.

[4] Myers, R, Classical And Modern Regression With Applications. Boston: PWS-KENT Publishing Company, 1990, Surabaya.

[5] Rousseeuw, P, J, Least Median of Squares. Journal of The American Statistician Association Vol.76, No 388: 871-880,1984, Jakarta. 